\title{
Influence of Auxin Concentration on in vitro Rooting of Chrysanthemum morifolium Ramat
}

\author{
Soo Cheon Chae \\ Department of Horticultural Science, College of Industrial Sciences, Kongju National University, \\ Daehak-ro 54, Yesan-kun, Chungnam, 32439, Korea. \\ http://dx.doi.org/10.13005/bbra/2104
}

(Received: 15 April 2016; accepted: 02 June 2016)

\begin{abstract}
Efficient in vitro rooting of Chrysanthemum morifolium Ramat., using hormone free media with different concentrations of auxins was developed. In this study we used three different auxins at various concentrations $(0,0.1,0.5$ and $1.0 \mathrm{mg} / \mathrm{L}$ ) of IAA (Indole3-acetic acid), IBA (Indole-3-butyric acid) and NAA (1-Naphthaleneacetic acid) for root development in Chrysanthemum morifolium. Shoot explants from in vitro culture were grown on a medium to determine the potential of rooting frequency, number of roots per explant and root length. However, $\mathrm{SH}$ medium with $1 \mathrm{mg} / \mathrm{L}$ of (IBA) induced the highest number $5.7 \pm 0.5$ of root per explant among the three different concentrations of auxin used followed by (IAA) and NAA. The highest root length $36.2 \pm 3.3$ was achieved in SH medium with $1 \mathrm{mg} / \mathrm{L}$ of IAA and lesser number of roots and root length were developed in NAA. The in vitro rooted plants were hardened and acclimatized in the greenhouse and successfully $(100 \%)$ transplanted to the field. Protocols were developed in the present investigation for cloning and large scale plant production of Chrysanthemum $(C$. morifolium Ramat.)
\end{abstract}

Keywords: Chrysanthemum morifolium, Root regeneration, Auxin.

Chrysanthemum (C. morifolium Ramat.), also known as Autumn Queen, and is one of the high value ornamental species found in worldwide. It is globally the second economically most important floricultural and vegetatively propagated cash crop following rose $\mathrm{e}^{1,2}$. Now a days, the dried capitulum of C. morifolium, Chrysanthemi Flos, is an most valuable medicinal material in China, Japan, Korean and other countries ${ }^{3,4}$, which is used for "scattering cold", " "cleaning heat and toxin" and "'brightening eyes”. Recently few researchers investigated Chrysanthemum (C. morifolium Ramat.) has various medicinal properties, such as antibacterial,

\footnotetext{
* To whom all correspondence should be addressed. Tel: +82-41-330-1223; Fax: +82-41-330-1229; E-mail:scchae@kongju.ac.kr
}

antiviral, anti-inflammatory activities ${ }^{6-10}$. It is also widely used as a food supplement or herbal tea, and is considered as a healthy food ${ }^{4,11}$.

Chrysanthemum morifolium Ramat. is cultivated widely in China. Its flower head is a popular traditional medicine called as 'Ju Hua' in Chinese, which has been listed in Chinese Pharmacopoeia ${ }^{5}$ as Chrysanthemi Flos. The flower of Chrysanthemum Morifolium Ramat. (CM) is widely used as a healthy beverage and medicine due to its unique flavor, color, and health benefits. Its anti-oxidation, vasoactive effects and antiischemia /reperfusion injury action have been proved in animal tests and clinic studies ${ }^{12}$. The healthy benefits of CM are confirmed to be connected with the flavonoids, such as luteolin, luteolin-7-O-2-D-glucoside, acacetin-7-O-2-Dglucoside, apigenin-7-O-2-D-glucoside, etc. ${ }^{13-15}$. Luteolin is a natural flavone and it is distributed extensively in the vegetable kingdom. In clinic, 
luteolin can relieve a cough, make expectoration easy, antiphlogosis. In vivo, it has the functions of antivirus, strong antimicrobial activity and reduces cholesterol and serum lipid. Luteolin-7-O2-D-glucoside could be biotransformed to their aglycone forms-luteolin (3', 4', 5, 7 tetrahydroxyflavone) in intestine by action of microorganism when the extract of CM was orally administrated $^{16}$. Caffeoylquinic acids and flavonoids, such as luteolin, apigenin and their glucosides are the actual bioactive compounds of Chrysanthemum plants ${ }^{17}$.

Chrysanthemum is one of the most popular cut flowers in India as well as in international market and it occupies an important position in the world cut flower trade. To get trueto-type plants, commercial cultivars are mostly propagated by means of vegetative cuttings or suckers. The market for ornamentals has steadily increased over the last few years and a continued period of growth is expected with the opening of new markets in developing countries like India.

The modern trends of plant micropropagation based on cell and tissue culture techniques are able to increase the efficiency of breeding processes ${ }^{18,19}$. They offer opportunities for rapid clonal propagation of some unique, superior genotypes ${ }^{20,21}$. Many researchers have reported for plant regeneration from different plant organs of C. morifolium. Recently, many research has been studied on the development of shoot organogenesis and plant regeneration from petal $^{22,23}$, leaf ${ }^{24}$, and stem ${ }^{25}$ explants cultures of $C$. morifolium for enhanced micropropagation system.

In vitro rooting of $C$. morifolium is one of the most valuable factors regulating the growth and micropropation. Therefore, aim of this study was to find out the suitable growth regulators for rapid root proliferation from young stem explants of C. morifolium.

\section{MATERIALSAND METHODS}

\section{Plant materials}

Young shoots were collected from 1years-old plants of $C$. morifolium growing in the green house of the Chungnam National University, Daejeon, Korea. For establishment of in vitro shoot cultures, the leaves from young shoots were eliminated and cutted around $5 \mathrm{~cm}$ in length. These explants were washed with tap water for 5-10 minutes and were surface sterilized with $70 \%(\mathrm{v} / \mathrm{v})$ ethanol for $30 \mathrm{sec}$ and 1\% sodium hypochlorite solution for $10 \mathrm{~min}$. The explants were then rinsed thoroughly with sterilized distilled water and were incubated on $50 \mathrm{~mL}$ of hormone free MS (Murashige and Skoog, 1962) ${ }^{26}$ basal medium in Magenta box under the light condition. The basal medium consisted of mineral salts and vitamins supplement together with $30 \mathrm{~g} / \mathrm{L}$ of sucrose and 8 $\mathrm{g} / \mathrm{L}$ of Phytagar as a solidifying agent. The $\mathrm{pH}$ of the medium was adjusted to 5.8 before adding the Phytagar and sterilized by autoclaving at $121^{\circ} \mathrm{C}$ for 20 minutes. After 4 weeks cultured elongated shoots were obtained and maintained under controlled environmental conditions until used.

\section{Promoting root regeneration with auxin}

Different auxins such as NAA (1Naphthaleneacetic acid), IBA (Indole-3-butyric acid) and IAA (Indole-3-acetic acid) and their different concentrations of $0,0.1,0.5$ and $1.0 \mathrm{mg} / \mathrm{L}$ were used in combination with hormone $\mathrm{SH}$ medium for efficient root regeneration in C. morifolium. Five segments of $1 \sim 2 \mathrm{~cm}$ long shoots were cultured on Magenta box containing $50 \mathrm{ml}$ each of the respective medium. These basal media, consisted of salts and vitamins, were solidified with $0.3 \%$ Gelrite and supplemented with 3\% (w/v) sucrose. The $\mathrm{pH}$ of the medium was adjusted to 5.8 prior to the addition of Gelrite and autoclaved at $121^{\circ} \mathrm{C}$ with the pressure of $1.1 \mathrm{~kg} \mathrm{~cm}^{-2}$ for $20 \mathrm{~min}$. Cultures were then incubated at $25 \pm 1^{\circ} \mathrm{C}$ with a 16 - $\mathrm{hr}$ photoperiod per day under the standard cool and white florescent tubes. All experiments were carried out in triplicate. Rooting efficiency, average number of root per explant and root length were measured at 4 weeks after incubation.

\section{Transferring plantlets to green house condition}

Regenerated plantlets were maintained continuously under the in vitro condition until the roots become well developed. After 8 weeks, the rooted plants were then transferred to the pots containing autoclaved vermiculite soil. Immediately after transplantation, the plants along with the pots were covered with moist polythene bag to prevent from desiccation. To reduce sudden shock, the pots were kept in a growth-controlled room for 7-15 days. After two to three days, the polythene bags were gradually perforated to expose the plants to natural environment. The bags were then completely 


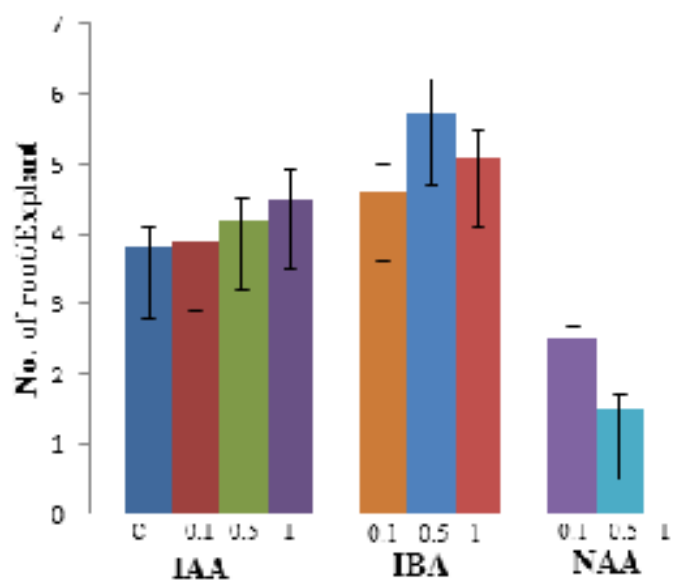

AUXIN mg/L

Fig. 1. Response of different concentrations of auxins on number of root regeneration from excised stem of Chrysanthemum morifolium after four weeks of in vitro culture.

removed after 10-15 days when the plantlets appeared to be self-supportive. At that stage, the plantlets were placed in natural environment for 310 hours daily. Finally, after 15-20 days, they were transferred to a green house condition.

Statistical analysis

The data obtained was analyzed as mean \pm standard deviation from 50 shoot explants tested.

\section{RESULTSAND DISCUSSION}

\section{Efficient root regeneration}

For better in vitro root regeneration, previous studies reported $\mathrm{SH}$ basal media was most suitable for root organogenesis in Chrysanthemum morifolium ${ }^{27}$. The type of medium has been found to play an important role in the root regeneration of $C$. morifolium. In order to determine for most efficient root regeneration, stem explants of $C$. morifolium were cultured on SH basal medium supplemented with different auxin concentration $(0,0.1,0.5,1.0 \mathrm{mg} / \mathrm{L}$ each of IAA, IBA, NAA) containing $30 \mathrm{~g} / \mathrm{L}$ sucrose and $3 \mathrm{~g} / \mathrm{L}$ gelrite. The more number of root and length was achieved in IAA, IBA and were not formed root in NAA. Among these concentrations higher root number $5.7 \pm 0.5$

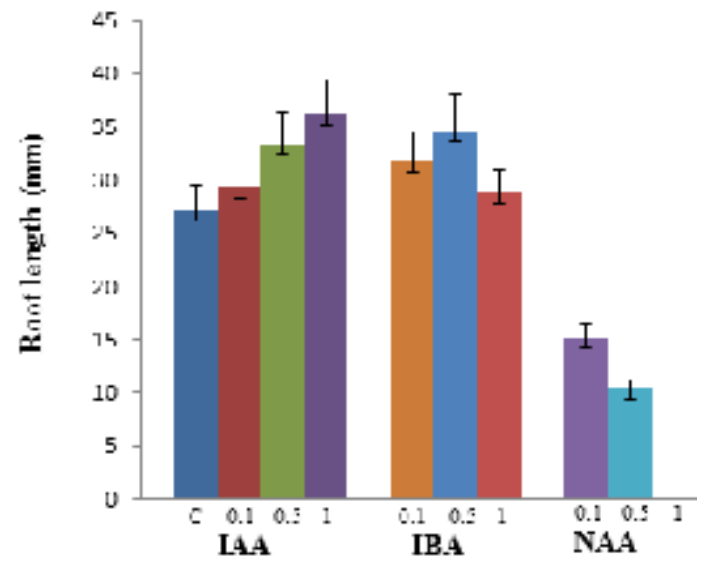

AUXIN mgl

Fig. 2. Response of different concentrations of auxins on root length from excised stem of Chrysanthemum morifolium after four weeks of in vitro culture

was developed at $1 \mathrm{mg} / \mathrm{L}$ IBA. These results were showed in figure 1 . The higher level of root length was showed $36.2 \pm 3.3$ at $1 \mathrm{mg} / \mathrm{L}$ IAA and results were showed in figure 2 . Although when increasing the concentration of IAA and IBA showed increases root number and length, but in NAA increased concentration showed less number of root and length. Different growth regulators involved the induction and enhanced the root number as well as their length were reported previously ${ }^{28,29}$. Roots are mostly induced in the presence of an auxin. IAA, IBA and NAA promoted high percentage of rhizogenesis in general. However, in the present study, IAA showed just a little promotive effect on root induction. On the other hand, IBA showed the most positive effect on induction and elongation of roots among the different auxins used in this study. Such an effect of NAA was also observed by Taylor ${ }^{30}$ in tomato. Moreover, numerous studies have indicated that, among the common auxins, NAA is the most effective auxin for induction of root regeneration ${ }^{31,32}$. IBA improved the root regeneration has been investigated earlier in Passiflora foetida ${ }^{33}$. In previous studies reported without growth regulators roots were regenerated 
from Chrysanthemum morifolium Ramat.) $)^{34}$. In this study, different type of auxin could promote in root regeneration although different concentrations of auxin were used in Chrysanthemum morifolium Ramat.).

\section{CONCLUSION}

In the present study an efficient in vitro root propagation protocol has been developed for Chrysanthemum (C. morifolium Ramat.). A very good number of shoots were multiplied and almost all the shoots were developed roots in this method. It reduced time, energy and cost of production of micropropagated plantlets and increased the possibility of survival in the field condition. This protocol can be used for large scale production of superior and disease free plants and supplied to the farmers at low cost as standard stock planting material. This information indicates a useful for further advance study in promoting commercial root production via gene transformation in the future.

\section{REFERENCES}

1. Teixeira da Silva, J.A., Chrysanthemum: advances in tissue culture, cryopreservation, postharvest technology, genetics and transgenic biotechnology. Biotechnol. Adv., 2003; 21, 715766.

2. Van Der Ploeg, A., Heuvelink, E. The influence of temperature on growth and development of chrysanthemum cultivars: A review. J. Hortic. Sci. Biotechnol. 2006; 81, 174-182.

3. Lai, J.P., Lim, Y.H., Su, J., Shen, H.M., Choon, N.O., Identification and characterization of major flavonoids and caffeoylquinic acids in three Compositae plants by LC/DAD-APCI/MS. $J$. Chramatogr. B, 2007; 848(2), 215-225.

4. Jin, M., Zhu, Z.B., Guo, Q.S., Shen, H.J., Wang, Y.R., Growth and accumulation of bioactive compounds in medicinal Chrysanthemum morifolium Ramat.cv. 'Chuju' under different colored shade polyethylene. J. Med. Plants Res., 2012; 6, 398-404.

5. Chinese Pharmacopoeia Committee (Ed.), 2010. Pharmacopoeia of the People's Republic of China. Chinese Edition 2010, Part I. China Medico-Pharmaceutical Science and Technology Press, Beijing, p. 292.

6. Ukiyaa, M., Akihisaa, T., Tokuda, H., Cancer Lett, 2002; 177, 7.
7. Lee, J.S., Kim, H.J., Lee, Y.S., A new anti-HIV flavonoid glucuronide from Chrysanthemum morifolium. Planta Med. 2003; 9, 859-861.

8. Kima, I.S., Koppulaa, S., Parka, P.J., Chrysanthemum morifolium Ramat (CM) extract protects human neuroblastoma SH-SY5Y cells against $\mathrm{MPP}^{+}$induced cytotoxicity. $J$. Ethnopharmacol. 2009; 126, 447.

9. Tsuji-Naito, K., Saeki, H., Hamano, M. Inhibitory effects of Chrysanthemum species extracts on formation of advanced glycation end products. Food Chem; 2009; 116:854-859.

10. Lii, C.K., Lei, Y.P., Yao, H.T., Hsieh, Y.S., Tsai, C.W., Liu, K.L., Chen, H.W., Chrysanthemum morifolium Ramat. reduces the oxidized LDLinduced expression of intercellular adhesion molecule-1 and E-selectin in human umbilical vein endothelial cells. J. Ethnopharmacol., 2010; 1, 213-220.

11. Lin, L.Z., Harnly, J.M., Identification of the phenolic components of chrysanthemum flower (Chrysanthemum morifolium Ramat), Food Chem. 2010; 120, 319-326.

12. Li LP, Jiang HD, Wu HH, Zeng S. Simultaneous determinationof luteoline and apigenin in dog plasma by RTHPLC. J. Pharm Biomed Anal. 2004; 37:615-620.

13. Hertog, MGL, Hollman PCH, Putte B. Content of potentially anticarcinogenic flavonoids of tea infusion, wines and fruit juice. J Agric. Food Chem. 1993; 41: 1242-1246.

14. Hertog MGL, Feskens EJM, Hollman PCH, Katan MB, Kromhout D. Dietary antioxidant flavonoids and risk of coronary heart disease: the Zutphen Elderly Study. The Lancet. 1993; 342: 1007-1011.

15. Hollman, PCH, Hertog MGL, Peter CH, Katan MB. Analysis and health effects of flavonoids. Food chem.1996; 57:43-46.

16. Day AJ, DuPont M S, Ridley S, Rhodes M, Rhodes MJC, Morgan MRA, Williamson G. Deglycosylation of flavonoid and isoflavonoid glycosides by human small intestine and liver ${ }^{2}$ glucosidase activity. FEBS Letters.1998; 436: 71-75.

17. Liu, F., Ong, E.S., Li, Y.S.F., A green and effective approach for characterisationand quality control of Chrysanthemum by pressurized hot water extraction in combination with HPLC with UV absorbance detection. Food Chem., 2013; 141, 1807-1813.

18. ROUT, G.R., PALAI, S.K., PANDEY, P., DOS, P. Direct plant regeneration of Chrysanthemummorifolium Ramat., influence of explant source, age of explant, culture environment, carbohydrates nutritional factors 
and hormone regime, Proc. Nat. Acad. Sci. India, 1997; 67(8): 57-66

19. ROUT, G.R., DOS, P. 1997. Recent trends in the biotechnology of Chrysanthemum, a critical review, Scientia Horticulturae 69: 239-257

20. SARKER, R.H., SHAHEEN, I. In vitro propagation of Chrysanthemum morifolium through callus culture, Plant Tissue Cult, 2001; 11(1): 85-91

21. TRIGIANO, R.N., MAY, R.A., GRAY, D.J. Advances in tissue culture of Chrysanthemum morifolium In: Dallos M.P. (Ed.)- Agricultural Biotechnology, a focus on the improvement of plants ACEVIV 2001.

22. Xue JP, Yu M, Zhang AM. Studies on callus induced from leaves and plantlets regeneration of the traditional Chinese medicine Chrysanthemum morifolium. Zhongguo Zhong Yao Za Zhi. 2003; 28(3): 213-216

23. Nahid JS, Shyamali S, Kazumi H. High frequency shoot regeneration from petal explants of Chrysanthemum morifolium Ramat. in vitro. Pak J Biol Sci. 2007; 10(19): 33563361.

24. Xue JP, Yu M, Zhang AM. Studies on callus induced from leaves and plantlets regeneration of the traditional Chinese medicine Chrysanthemum morifolium. Zhongguo Zhong Yao Za Zhi. 2003; 28(3): 213-216

25. Lu CY, Nugent G, Wardley T. Efficient, direct plant regeneration from stem segments of chrysanthemum (Chrysanthemum morifolium Ramat. cv. Royal Purple). Plant Cell Rep. 1990; 8(12): 733-736.

26. Murashige, T., Skoog, F. A revised medium for rapid growth and bio assays with Physiol Plant.,
1962; 15: 473-497.

27. Soo Cheon Chae 2014. Influence of media on in vitro root regeneration and micropropagation of Chrysanthemum morifolium Ramat cv. Hwiparam. Life Science Journal 2014; 11

28. Balvanyos, I., Kursinszki, L. and Szoke, E. The effect of plant growth regulators on biomass formation and lobeline production of Lobelia inflata L. hairy root cultures. Plant Growth Reg, 2001; 34 : 339-345.

29. Balestri, E. and Bertini, S. Growth and development of Posidonia oceanica seedlings treated with plant growth regulators : Possible implications for meadow restoration. Aquat. Bot, 2003; 76 :291-297.

30. Taylor, J.L.S. and Van Staden, J. Plant-derived smoke solutions stimulate the growth of Lycopersicon esculentum roots in vitro. Plant Growth Reg, 1998; 26 :77-83.

31. Kitto, S.L. and Young, M.J. In vitro propagation of Carrizo citrange. Hort. Science, 1981; 16: 305-306.

32. Johnson, B.B. In vitro propagation of Episcia cupreata. Hort Science, 1978; 13:596.

33. Mahipal S. Shekhawat, N. Kannan, M. Manokari, C.P. Ravindran. In vitro regeneration of shoots and ex vitro rooting of an important medicinal plant Passiflora foetida L. through nodal segment cultures. Journal of Genetic Engineering and Biotechnology, 2015; 13, 209 214.

34. Smaranda vântu. Organogenesis in chrysanthemum morifolium ramat (cultivar "romica") callus cultures. Analele_tiincifice ale Universitcii “Al. I. Cuza” Ia_i Tomul LII, s. II a. Biologie vegetal, 2006 